\title{
ENTRE O DISCURSO SOLIDÁRIO E A AÇÃO PRAGMÁTICA DA COOPERAÇÃO BRASILEIRA EM MOÇAMBIQUE: os casos dos projetos de implantação da fábrica de medicamentos antirretrovirais e o ProSavana ${ }^{1}$
}

\author{
Elga Lessa de Almeida *
}

\begin{abstract}
A cooperação brasileira com países africanos ganhou importante relevo ao longo do governo de Lula da Silva, apoiada pelo discurso da solidariedade internacional e da existência de uma dívida histórica com a África, bem como por uma prática que busca, sobretudo, estruturar setorialmente as demandas desses países, sem impor condicionalidades. Percebe-se, no entanto, que a presença brasileira em Moçambique - país que recebeu especial atenção no governo Lula da Silva - aponta para uma ambivalência dessa cooperação. Ao mesmo tempo em que o discurso propaga uma cooperação não vinculada a interesses econômicos, é observada a presença de grandes empresas brasileiras como benfeitoras nos projetos da cooperação, ou mesmo diretamente interessadas nos resultados produzidos por esses projetos. Nesse sentido, este trabalho procura evidenciar essa ambivalência e refletir sobre ela, por meio da análise de dois projetos que vão alcançar um significado importante para a cooperação técnica brasileira: o projeto da implantação da fábrica de medicamentos antirretrovirais e o Programa de Cooperação Tripartida para o Desenvolvimento Agrícola da Savana Tropical em Moçambique, o ProSavana.
\end{abstract}

PalAVRAS-CHAVE: Cooperação brasileira. Interesses. Moçambique. Fábrica de medicamentos. ProSavana.

\section{INTRODUÇÃO}

Na primeira década deste século, a cooperação brasileira para o desenvolvimento internacional (COBRADI) tornou-se uma importante pauta da política externa brasileira e, em decorrência, muitas expectativas foram depositadas na intensificação e alargamento das práticas cooperativas do país. Os dois mandatos do governo de Luís Inácio Lula da Silva (2003-2010) representaram não só o aumento dos investimentos na cooperação como o início da contínua preocupação com sua sistematização e aperfeiçoamento. Mesmo com o arrefecimento dos investimentos brasileiros na COBRADI ao longo do governo Dilma Rousseff, essa preocupação persiste, e os primeiros projetos iniciados têm se prestado à análise sobre seus interesses, limites e possibilidades.

* Universidade Federal do Recôncavo da Bahia. Centro de Cultura, Linguagens e Tecnologias Aplicadas (CECULT).

Rua do Imperador, n. 09, Cais de Araújo Pinho. Cep: 44200000. Santo Amaro da Purificação - Bahia - Brasil. elgalessa@ufrb.edu.br

${ }^{1}$ Este artigo resulta do projeto "A Cooperação Brasileira para o Desenvolvimento Internacional com Angola e Mocambique: entre o discurso solidário e prática pragmática" (chamada MCTI/CNPq/MEC/CAPES n. 43/2013) da Universidade Federal da Bahia
Apesar de os primeiros relatórios (IPEA; ABC, 2010; IPEA; ABC, 2013) do governo brasileiro indicarem que o maior aporte de recursos da cooperação foi aplicado em projetos na América do Sul, foi na África que essa cooperação representou uma mudança para o Sul do posicionamento brasileiro na arena internacional. Aliada à intensificação da cooperação para o desenvolvimento, a presença brasileira no continente foi acompanhada da promoção governamental para o aumento das relações políticas e econômicas com os países africanos, o que significou a abertura de novas embaixadas, visitas presidenciais recorrentes, a intensificação das trocas comerciais e a entrada de importantes empresas brasileiras no mercado africano.

O contexto que aglutinava diversos interesses brasileiros à cooperação foi separado por um discurso governamental de desinteresse econômico, que afirmava as diretrizes da cooperação brasileira a partir da solidariedade entre os países do Sul, da não imposição de condicionalidades e do respeito à soberania do país parceiro. Se, por um lado, esse discurso marcava o desejo por uma atuação destoante 
da cooperação tradicionalmente prestada pelos países desenvolvidos, a presença brasileira na África revelou, por outro lado, que as relações e diferentes interesses podem estar imbricados de diferentes formas.

O caso da cooperação brasileira em Moçambique é bastante ilustrativo para compreender as interfaces entre cooperação e negócios, considerando o esforço para o aumento da presença brasileira nesse país nos últimos anos. Ao longo do século XX, as relações entre Brasil e Moçambique caracterizavam-se por um relativo afastamento, principalmente marcadas pelo posicionamento brasileiro de apoio a Portugal na questão da independência das colônias africanas. Aliada a questões de política doméstica e da guerra civil (1977-1992), a ausência de produtos moçambicanos que alavancassem as relações entre os países mantiveram-nas em um patamar de pouca relevância, somente sobrestado com algumas ações pontuais, como a participação brasileira na missão de paz organizada pelas Nações Unidas e, posteriormente, com a criação da Comunidade de Países de Língua Portuguesa (CPLP). No início do século XXI, a intensificação da exploração de importantes recursos minerais em solo moçambicano e o novo posicionamento da política externa brasileira redimensionaram essas relações.

É nesse contexto que projetos da coope-

O ração brasileira tornaram-se um importante insN trumento de aprofundamento da relação entre esses países. Dois projetos, especialmente, são exemplares para se compreender esse processo: a implantação da fábrica de medicamentos antirretrovirais e o Programa de Cooperação Tripartida para o Desenvolvimento Agrícola da Savana Tropical em Moçambique - ProSa고 vana. Por meio desses projetos, a existência de imbricações entre cooperação e interesses econômicos pode ser analisada, verificando-se a adequação do discurso brasileiro à sua prática. Nesse sentido, este artigo procura evidenciar a ambivalência da COBRADI e refletir sobre ela, trazendo aportes para o aprofundamento da análise da atuação brasileira em Moçambique.

\section{A COOPERAÇÃO BRASILEIRA EM MOÇAMBIQUE E O CONTEXTO MO- ÇAMBICANO}

O alto grau de dependência de ajuda que Moçambique tem experimentado, desde o final da década de 1980, fez com que o país se tornasse um verdadeiro "laboratório" de cooperação internacional. O fracasso do projeto socialista levou a Frente de Libertação de Moçambique (FRELIMO) a ceder às pressões para a abertura do mercado moçambicano e a descentralização da economia em troca do reescalonamento de sua dívida, do ingresso em algumas instituições internacionais e, sobretudo, da obtenção de ajuda emergencial do Ocidente. A partir daí, várias modalidades de cooperação foram recebidas pelo governo moçambicano, passando de uma forte atuação de organizações não governamentais, na prestação de ajuda alimentar emergencial, à atual ajuda direta ao orçamento (Abrahamsson; Nilsson, 1994; Hanlon, 1991; Oppenheimer, 2006).

Diante desse contexto de dependência de ajuda, o Brasil elegeu Moçambique para pôr em prática os projetos mais emblemáticos da estratégia da política externa no continente africano. Os últimos dados divulgados sobre a cooperação brasileira no país indicaram que, em 2010, foram investidos $\mathrm{R} \$ 8.625 .830 \mathrm{em}$ Moçambique, com preferência para projetos de cooperação técnica de natureza estruturante (IPEA; ABC, 2013). Diferentemente da ajuda direta ao orçamento e dos empréstimos concessionais realizados pelos países desenvolvidos, o Brasil elegeu a cooperação técnica como abordagem preferencial de sua atuação no país, empreendendo ações que objetivassem o fortalecimento estrutural de alguns setores, principalmente saúde, agricultura e educação. Por ser uma modalidade com menor aporte de recursos, a cooperação brasileira tem caráter complementar e, em geral, pouco significativa dentro do universo da ajuda recebida por Moçambique. 
Apesar de representar uma diminuta parcela da cooperação recebida pelo país africano, os projetos de implantação da fábrica de medicamentos antirretrovirais e do ProSavana têm impactado de forma considerável na relação entre os países. As polêmicas em torno dos interesses que envolvem a cooperação brasileira foram evidenciadas nesses projetos, o que tem possibilitado uma análise sobre a adequação do discurso da cooperação brasileira à sua prática no continente africano. A seguir, analisaremos os dois projetos e suas diferentes dinâmicas.

\section{O projeto da fábrica de medicamentos an- tirretrovirais: exemplo de cooperação bra- sileira solidária}

Na sua primeira viagem oficial ao continente africano, em 2003, o então Presidente Lula da Silva comprometeu-se publicamente a desenvolver um programa de atenção ao problema do HIV e AIDS em Moçambique, por meio da instalação de uma fábrica de medicamentos antirretrovirais. Nessa ocasião, foi assinado um protocolo de intenções sobre cooperação científica e tecnológica na área de saúde, que iniciou as negociações para o desenvolvimento do projeto. Essas iniciativas, no entanto, não haviam sido precedidas de qualquer consulta ou estudo de viabilidade por parte das entidades que viriam a ser vinculadas ao projeto, do que decorreu a necessidade do decurso de cinco anos de estudos pela Fundação Oswaldo Cruz (FIOCRUZ), entidade escolhida para executar o projeto.

A proposta concebida pelo governo brasileiro em parceria com o governo moçambicano previa um conjunto de ações que extrapolavam a mera instalação física da fábrica de medicamentos antirretrovirais; incluía a capacitação técnica dos funcionários moçambicanos para trabalhar na fábrica e o fortalecimento do órgão regulador de medicamentos de Moçambique, considerando que, para a inserção dos medicamentos produzidos na fábrica no mer- cado internacional, exige-se a observância de normas de padrão internacional. Nesse sentido, todo planejamento do projeto considerou o mercado regional africano para a venda do medicamento, bem como a autossuficiência de Moçambique na produção, com uma política de saúde mais abrangente e acessível à sua população. Nota-se que esse projeto marca a passagem de uma cooperação brasileira, na área de saúde, predominantemente voltada para a realização de pesquisas de iniciativa individual de pesquisadores brasileiros, para uma cooperação de caráter estruturante, dirigida ao fortalecimento de um setor estratégico de atendimento da saúde pública.

Tratava-se de um projeto inédito no continente, baseado na expertise brasileira de política de atendimento a portadores de HIV e AIDS. Desde a década de 1990, o Brasil vem se consolidando como referência internacional nessa política, em razão do seu caráter universal, que engloba prevenção, diagnóstico e tratamento. Essa política, em grande parte, é reconhecida pela licença compulsória de patentes de medicamentos voltados para o tratamento de HIV e AIDS, suspendendo-se, temporariamente, o direito de exclusividade das patentes das indústrias farmacêuticas, medida sem a qual seria inviabilizada a manutenção da política pública de atendimento gratuito. Por ser um programa de atendimento bastante abrangente, a política brasileira tornou-se referência internacional e, nesse sentido, passou a fazer parte do portfólio da cooperação técnica brasileira, principalmente com países sul-americanos e países africanos de língua oficial portuguesa.

Muito diferente é a realidade da política moçambicana para o tratamento de HIV e AIDS. A África Subsaariana é considerada a região de maior incidência de infectados pelo vírus HIV, estando Moçambique entre os dez países mais afetados. Segundo as estimativas apresentadas pela UNAIDS, agência das Organizações Unidas para a AIDS, referente ao ano de 2013, Moçambique possuía cerca de 1.600.000 pessoas vivendo com HIV e AIDS, 
sendo 1.400 .000 adultos acima de 15 anos, e 190.000 crianças infectadas entre 0 e 14 anos. Apesar de o governo moçambicano reconhecer que HIV e AIDS são entraves ao desenvolvimento do país, a resposta governamental ao problema não tem sido suficiente para travar a progressão dos dados na velocidade esperada (UNAIDS, 2015). Ao longo da última década, o Ministério da Saúde de Moçambique (MISAU) contou com dois instrumentos orientadores para o tratamento do tema: os Planos de Ação para Redução da Pobreza Absoluta (PARPAs, posteriormente denominado PARPs) e os Planos Estratégicos Nacionais de Combate ao HIV/ SIDA (PEN I, II e III). Nota-se, no entanto, que a escassez de recursos domésticos e o alto grau de dependência de ajuda externa tornam a articulação de uma resposta eficiente mais difícil.

A resposta ao HIV/SIDA em Moçambique continua a ser essencialmente sustentada pela assistência externa. Em 2011, os recursos internacionais representaram cerca de 95\% do total de despesas para o HIV no país. Recursos públicos domésticos foram responsáveis por 5,1\% da resposta (US\$ 13,4 milhões) e recursos privados moçambicanos corresponderam a uma taxa inferior a $0,1 \%$, com US\$ 230 mil. A maior contribuição foi feita pelo Governo dos Estados Unidos da América, cuja contribuição totalizou US\$ 187 milhões de dólares e foi responsável por 72\% da resposta à SIDA em Moçambique. Dentre os outros financiadores estavam o Fundo Global para o HIV, TB e Malária (US\$ 23 milhões), financiadores bilaterais (US\$ 11 milhões), agências da ONU (US\$ 11 milhões), ONGs internacionais e filantrópicas (US\$ 10 milhões), e outras organizações multilaterais (US\$ 5 milhões). (UNAIDS, 2014, p. 23, tradução nossa).

A ajuda norte-americana para o tratamento do HIV e AIDS é executada, basicamente, por meio de organizações não governamentais, a partir das políticas traçadas pela iniciativa The U. S. President's Emergency Plan for AIDS Relief (PEPFAR), fundo governamental que objetiva combater o HIV e AIDS em diferentes países, sendo comumente acessado por organizações não governamentais criadas por universidades norte-americanas para a execu- ção direta de projetos. No caso de Moçambique, essas organizações não governamentais têm se incumbido do atendimento direto à população nos centros de saúde.

Apesar do importante aporte de recursos, a ajuda norte-americana tem gerado impactos controversos sobre o sistema de saúde pública moçambicana, conforme apontou um cooperante brasileiro em Moçambique, entrevistado em 2012. Segundo informações prestadas pelo entrevistado, a participação dessas organizações não governamentais norte-americanas contribuiu para enfraquecer o sistema de saúde pública do país, em razão do braindrain diferenciado praticado por essas instituições. Ao invés da saída do profissional moçambicano do país, o profissional migra do sistema público de saúde para o privado, sendo atraído por uma condição muito mais vantajosa oferecida pelas ONGs, com recebimento salarial em dólar.

Diante desse contexto crítico, observa-se que a resposta do governo moçambicano é profundamente dependente da ajuda externa recebida, assim como em outros níveis da atuação governamental. Assim como os planejamentos nacionais são pautados pelos doadores internacionais, as políticas de atenção ao HIV e à AIDS parecem seguir essa regra e, apesar de todo o investimento realizado, Moçambique ainda se mantém entre os dez países com maior número de infectados pelo HIV. Nesse quadro, a proposta da cooperação brasileira para o tema parece inovadora e propõe um caminho inverso ao que tem sido trilhado, no sentido de empoderar o governo moçambicano com a criação de estruturas capazes de oferecer melhores condições de resposta aos desafios impostos pela presença do HIV e da AIDS no país.

Antes mesmo da conclusão dos estudos que decidiram pela viabilidade da implantação da fábrica de medicamentos antirretrovirais na província de Maputo, localizada na cidade de Matola, foram iniciadas as negociações sobre as bases em que se constituiriam o projeto e as contrapartidas de cada parceiro. A previsão inicial de custos para a instalação 
da fábrica foi de aproximadamente US\$21 milhões, cabendo ao Brasil, além da transferência de toda a expertise relacionada à instalação da fábrica e à produção dos medicamentos, a doação de todos os equipamentos e insumos para o início do funcionamento das atividades. Da contrapartida moçambicana, caberia ao governo a compra da planta da fábrica e as obras de instalação, no valor orçado aproximado de US\$5,4 milhões (Lopes, 2013; Ministério da Saúde; Fiocruz, 2015).

Muitas dificuldades foram observadas na integralização do orçamento para a execução do projeto. A contrapartida do governo brasileiro, no valor de $\mathrm{R} \$ 13,6$ milhões, a ser consignado no orçamento do Ministério da Saúde e doado ao governo moçambicano, somente foi liberada no final de 2009, por meio da Lei $\mathrm{n}^{\mathrm{O}} 12.117$, de 14 de dezembro de 2009. Do lado moçambicano, o cronograma do projeto foi atrasado em razão da alegação de falta de recursos para compor o total da sua contrapartida. Com a intenção de viabilizar o projeto, durante a visita a Moçambique em 2008, o presidente brasileiro anunciou publicamente que a empresa brasileira Vale S.A. realizaria uma doação de US $\$ 4,5$ milhões ao governo moçambicano para viabilizar a fábrica. A partir da doação realizada pela Vale, o governo brasileiro teve a garantia de que o projeto seria viabilizado na prática. Em 2009, a empresa brasileira iniciou as obras na planta já comprada pelo governo moçambicano, uma antiga fábrica de soros na cidade de Matola, que foram concluídas em 2011, portanto, já no governo de Dilma Rousseff.

Nota-se que as dificuldades para a implantação de um projeto de tal envergadura não se limitaram à sua implantação física, mas demandaram a capacitação de um grupo de funcionários que atuasse segundo padrões internacionais da indústria farmacêutica. Diante da ausência de capital humano com formação nesse tipo de produção, a empresa Vale garantiu a contratação de um diretor de produção indicado pela FIOCRUZ para morar em Moçambique e trabalhar diretamente na fábrica.
Esse diretor ficaria responsável por coordenar as atividades de produção da fábrica, após a transferência da expertise brasileira e a capacitação dos funcionários contratados pelo governo moçambicano, 45 funcionários no total, sendo 15 contratados no período da inauguração, além dos 30 que eram da planta anterior da fábrica de soros (Lopes, 2013).

$\mathrm{Na}$ divisão dos trabalhos, uma empresa brasileira acabou por ingressar de forma pontual como uma das parceiras da cooperação, criando uma triangulação peculiar ao projeto. Registre-se que o anúncio da doação para a realização das obras da fábrica de medicamentos precedeu os acontecimentos que resultaram em um grande mal-estar gerado pela exploração da mina de carvão de Moatize pela Vale. Esse empreendimento exigiu o reassentamento de cerca de 700 famílias da província de Tete a partir do ano de 2009. As informações trazidas pelos noticiários locais denunciavam as péssimas condições de vida a que foram submetidos os reassentados e o descumprimento pela Vale S.A. dos acordos realizados em audiências públicas. Desde então, algumas manifestações realizadas pelos reassentados foram registradas, como o bloqueio de estradas e da linha férrea que dá acesso à mina. A inauguração da fábrica de medicamentos, em 21 de julho de 2012, foi uma grande oportunidade para a empresa brasileira tentar mitigar os efeitos negativos relacionados ao reassentamento provocado pela exploração da mina, promovendo, junto à mídia moçambicana, sua participação no projeto de cooperação.

Importa registrar que, até as vésperas da inauguração da fábrica, os cooperantes brasileiros sentiam certa resistência ao projeto dentro do próprio governo moçambicano. A implantação da fábrica marcou a passagem de uma política pública extremamente dependente de ajuda externa para uma que colocou o governo moçambicano no centro da gestão de uma área de política social fundamental para a atenção a HIV e AIDS. Isso traz como principal impacto a necessidade de orçamento suficiente para custear os gastos com funcionários, ma- 
nutenção e compra de insumos para a produção dos medicamentos, por meio de licitações que levem em consideração as especificações internacionais para a produção, além da estruturação do setor nacional de regulamentação de medicamentos, exigindo grande esforço por parte do governo moçambicano.

Apesar das dificuldades, a fábrica de medicamentos foi inaugurada em 21 de julho de 2012, com a presença do Vice-Presidente brasileiro Michel Temer e da governadora da cidade de Maputo, não havendo qualquer representação oficial de alto nível do governo moçambicano. Sob a denominação Sociedade Moçambicana de Medicamentos S. A, vinculada ao Instituto de Gestão de Empresas e Participação do Estado, órgão responsável pelos processos de privatização em Moçambique, a fábrica iniciou suas atividades, primeiramente, com o embasamento e rotulagem dos medicamentos vindos do Brasil e, em novembro de 2012, concluiu a fabricação da primeira remessa do antirretroviral Nevirapina 200mg. A cerimônia de entrega dos medicamentos e dos diplomas de conclusão de curso dos técnicos moçambicanos capacitados pela FIOCRUZ contou com a presença do agora ex-Presidente Lula, que reafirmou seu compromisso com as questões relacionadas ao desenvolvimento do continente africano (Lopes, 2013).

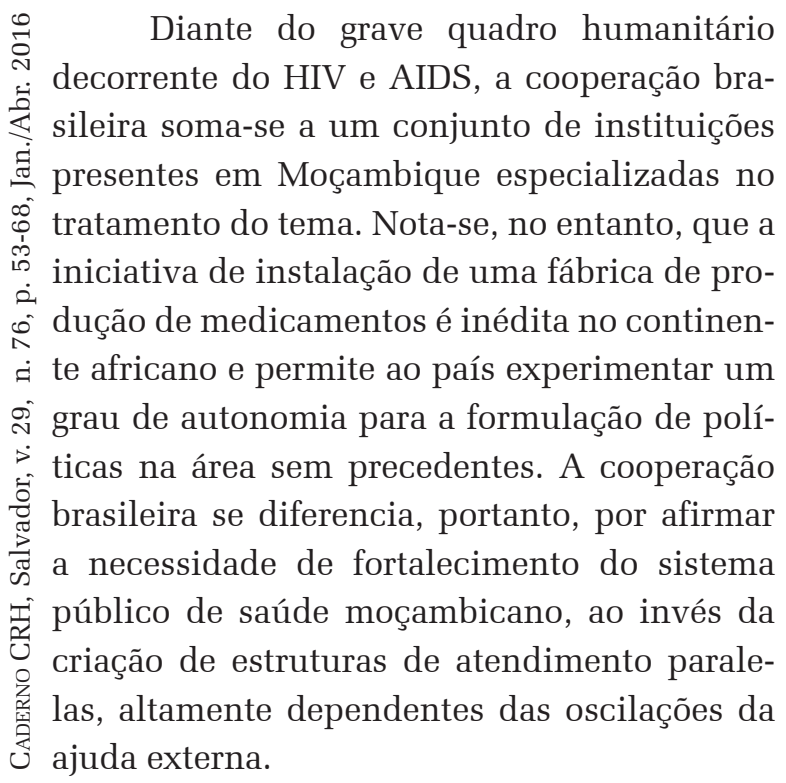

Apesar de sua importância e ineditismo, o projeto não é isento de críticas tanto do lado moçambicano como do brasileiro. A pesquisa em campo permitiu perceber o grande desconhecimento da população moçambicana a respeito do projeto, mesmo meses após a inauguração da fábrica. Algumas das críticas levantadas foram que a instalação da fábrica tinha por objetivo garantir ao Brasil o mercado africano para a venda de medicamentos, que o Brasil seria beneficiado por meio da venda de insumos para a fábrica e que o Brasil se utilizava do projeto para financiar as empresas dos equipamentos que foram comprados para a fábrica. Essas críticas desconsideravam pontos importantes do acordo de cooperação: 1) a Sociedade Moçambicana de Medicamentos é integralmente de propriedade do governo moçambicano, não detendo o governo brasileiro, ou qualquer instituição pública brasileira, qualquer percentual acionário ou direito sobre a produção dos medicamentos produzidos no âmbito da fábrica; 2) quanto à compra de insumos para a fábrica, tem-se que o Brasil não é produtor de insumos para a produção de medicamentos, importando os produtos da China e da Índia, após realização de processo licitatório devidamente acompanhado pela agência reguladora de medicamentos; e 3) a compra de maquinário junto à empresa brasileira decorreu, segundo cooperantes, das facilidades para a compra e transporte das máquinas dentro do Brasil, não se caracterizando como uma condicionalidade da cooperação.

Por outro lado, a vinculação da Sociedade Moçambicana de Medicamentos ao órgão responsável pelas privatizações, dentro do Estado moçambicano, trouxe insegurança entre os cooperantes brasileiros, diante da possibilidade de venda da fábrica pelo governo moçambicano. Nesse sentido, abriu-se a discussão se uma cooperação sem nenhuma condicionalidade é a melhor cooperação. Faz sentido o investimento em um projeto de cooperação quando não existe uma garantia de que os esforços serão utilizados para o objetivo inicial- 
mente proposto? Essa questão é colocada pela necessidade de instrumentalizar a cooperação de maior eficácia, com a correspondência entre o investimento realizado e o objetivo proposto.

Nota-se que, no caso da fábrica de medicamentos, a cooperação brasileira reafirmou os princípios orientadores da cooperação Sul-Sul e buscou diferenciar sua presença das demais agências estrangeiras. Apesar da possibilidade de o governo moçambicano se desfazer da fábrica, o posicionamento do governo brasileiro foi de respeito à soberania daquele Estado, não impondo qualquer condicionalidade sobre a fábrica e expressando, portanto, uma relação fundada na crença real da possibilidade de aperfeiçoamento da resposta do sistema público de saúde para a questão do HIV e AIDS por meio da reunião de esforços entre os países. Mesmo que do projeto possam advir vantagens para instituições como a FIOCRUZ - a maior visibilidade de sua presença no continente colaborou para um importante acordo com a Fundação Bill \& Melinda Gates na área de produção e exportação de vacinas para países africanos -, as vantagens porventura auferidas enquadram-se na ideia de benefício mútuo, o que reforça todos os participantes da arquitetura da cooperação.

\section{ProSavana: cooperação e negócios cami- nhando juntos}

Diferentemente da cooperação internacional no campo de saúde, a análise da cooperação técnica brasileira na área agrícola revela que, setorialmente, ela pode ter matizes bastante diferentes. As polêmicas geradas em torno do Programa de Cooperação Tripartida para o Desenvolvimento Agrícola da Savana Tropical em Moçambique (ProSavana) têm questionado se efetivamente a cooperação brasileira no setor pode contribuir para o desenvolvimento agrário e a segurança alimentar dos países parceiros. Apesar da afirmação contrária do lado brasileiro, denúncias de orga- nizações não governamentais moçambicanas apontam para a transferência de uma política agrícola baseada no latifúndio e na monocultura, que privilegia o agronegócio voltado para exportação em detrimento do fortalecimento dos pequenos agricultores, que estariam sendo expropriados de suas terras, o que aprofunda, ainda mais, a pobreza do país.

Essas denúncias surgiram em um contexto em que os países africanos aparecem como a grande fronteira agrícola mundial, por possuírem recursos naturais (terra e água) e mão de obra de baixo custo. Ao mesmo tempo em que a demanda por terras reflete a necessidade de outros países por commodities, essa posição é estimulada pela estratégia de atração de investimentos diretos estrangeiros de alguns governos africanos como forma de reverter o declínio da produção camponesa local. Desde a independência, a agricultura é considerada a base do desenvolvimento moçambicano, cabendo ao Estado a promoção do desenvolvimento rural para a satisfação crescente e multiforme das necessidades do povo e o progresso econômico e social do país (Moçambique, 2004). Nota-se, entretanto, que os dados do setor agrário revelam pouca capacidade de garantir a segurança alimentar de sua população, $70 \%$ dela residente no meio rural. O setor se caracteriza por uma produção agrícola estacionária, pouco eficiente na relação de rendimento por hectare e pouco integrada ao mercado. As políticas governamentais na área, por sua vez, experimentam grande instabilidade institucional e escassez de recursos (Mosca, 2014). Fatores internos, como a distribuição fundiária e o modelo da estruturação produtiva, aliados à guerra civil e aos fenômenos naturais (a grande seca da década de 1980, especialmente) são importantes para se compreender a atual situação do setor em Moçambique.

A abertura da economia moçambicana ao mercado, com a sobrevalorização de sua moeda, criou uma concorrência desleal entre os produtos agrícolas moçambicanos e os produtos sul-africanos. O recrudescimento dos efeitos da guerra, com a desarticulação 
da pouca infraestrutura física existente, como destruição de lojas, armazéns, estradas e pontes, levaram ao isolamento das áreas agrícolas e, consequentemente, ao impedimento da comercialização dos seus produtos. Aliada a esses fatores, a política de ajuda alimentar dos países doadores criava empecilhos para a recuperação da economia local, tendo em vista que os doadores não compravam o excedente da produção moçambicana, mas doavam ou vendiam os produtos in natura trazidos dos seus países a preços subvencionados, o que tornava os produtos locais mais caros em relação aos produtos importados, bloqueando o acesso dos produtores locais ao mercado. Conforme lembra o pesquisador moçambicano João Mosca, “apoiar, de forma massiva, a produção agrícola e, principalmente, de bens alimentares nos países pobres, seria criar a própria concorrência em espaços com eventuais vantagens comparativas e imporia reformas drásticas nas políticas agrárias dos países desenvolvidos” (2014, p. 27). Dessa forma, observou-se, na década de 1980, a transformação da economia rural em uma economia de troca, em que os camponeses deixaram de acreditar no dinheiro e passaram a exigir bens de consumo em troca direta do seu excedente de produção (Abrahamsson; Nilsson, 1994).

É nesse contexto que a cooperação técnica brasileira na área agrícola e de segurança of alimentar ingressa na realidade africana. Em ผ razão do sucesso brasileiro na exportação de grãos e da grande expertise acumulada por instituições como a Empresa Brasileira de Pesơ quisa Agropecuária (EMBRAPA), a demanda Co países africanos por cooperação no setor o agrícola e de segurança alimentar experimena tou um grande avanço. Nota-se que o portfóơ lio de projetos contempla desde a aplicação $\therefore$ de técnicas em campo ao fortalecimento das instituições gestoras da área, com grande inclinação para os chamados projetos estruturantes, em razão das vantagens deles resultantes: aumento do impacto social e econômico sobre o público-alvo da cooperação; maior sustentabilidade dos resultados dos programas e proje- tos; facilidade de mobilização de instituições brasileiras para a implementação de diferentes componentes dos programas ou projetos; e criação de espaço para a mobilização de parcerias triangulares com outros atores internacionais (IPEA; ABC, 2010).

Em grande medida, o avanço tecnológico empreendido desde a década de 1970 no setor agrícola brasileiro, por meio do acordo de cooperação entre Brasil e Japão para a criação do Programa Nipo-brasileiro para o Desenvolvimento dos Cerrados (PRODECER), serviu de inspiração para a concepção de um projeto de natureza similar na savana africana. Ao aliar o progresso técnico à disponibilização de crédito aos produtores, o sistema agrário brasileiro pôde unir-se aos sistemas industrial, mercantil, financeiro e tecnológico, formando o agronegócio, expressão da reunião do capital nacional e internacional para sua ampliação e inserção nos mercados (Clements; Fernandes, 2013). Esse processo, que se intensificou ao longo da década de 1980, acabou por reforçar as características da organização agrária brasileira, com a introdução da monocultura da soja voltada para exportação e forte concentração de terras por empresas multinacionais, em detrimento do pequeno agricultor e da população indígena.

A expansão da fronteira agrícola no cerrado não se deu, no entanto, sem conflitos, observando-se impactos negativos: extenso desmatamento de áreas do cerrado e da floresta amazônica; deslocamento de pequenos produtores rurais e comunidades indígenas; compactação e erosão do solo; contaminação dos recursos hídricos em razão do uso intensivo de pesticidas e fertilizantes químicos (Clements, 2013; Funada-Classen, 2013; Milhorance, 2013; Patriota, 2013). Os movimentos sociais passaram a reivindicar maior atenção aos conflitos no campo e maior investimento público na agricultura familiar, possibilitando, portanto, problematizar a estrutura agrária brasileira. Nesse sentido, ocupações de terras articuladas pelo Movimento dos Sem Terra (MST) por todo país e manifestações de peque- 
nos agricultores para reivindicação de programas de crédito diferenciados começaram a ser observados com maior frequência, resultando na criação do Programa Nacional de Fortalecimento da Agricultura Familiar (PRONAF) em 1996, por meio do Decreto $\mathrm{n}^{0}$ 1.946/96, e do Ministério Extraordinário da Política Fundiária, durante o governo de Fernando Henrique Cardoso. No governo Lula da Silva, essa política foi aprofundada com a criação do Ministério do Desenvolvimento Agrário (MDA), a expansão do PRONAF, a promulgação da Lei $n^{0} 11.326$, de 24/07/2006, que estabelece as diretrizes para a formulação da política nacional da agricultura familiar e empreendimentos familiares rurais, e a Lei $\mathrm{n}^{\mathrm{o}} 11.346$, de 15/09/2006, que cria o Sistema Nacional de Segurança Alimentar e Nutricional.

A parceria entre Brasil e Japão para o fortalecimento da ajuda em Moçambique, com base nos conhecimentos acumulados pelo Programa de Cooperação para o Desenvolvimento Agrícola dos Cerrados (PRODECER), foi anunciada em 2007, sendo o Memorando de Entendimento entre os três países assinado em 2009 e o Ajuste Complementar ao Acordo de Cooperação apenas concretizado em 2010. Segundo o acordo celebrado entre os três países, o ProSavana foi estruturado a partir de três projetos - ProSavana Projeto de Investigação, ProSavana Plano Diretor e ProSavana Projeto de Extensão e Modelos -, tendo por objetivo a criação de novos modelos de desenvolvimento agrícola no Corredor de Nacala. O programa foi orientado para o mercado e suas vantagens comparativas, sem desconsiderar, no entanto, os aspectos ambientais e socioeconômicos da atividade (ProSavana, 2015). O primeiro projeto a ser negociado foi o ProSavana PI, que conta

Quadro 1 - Composição do ProSavana

\begin{tabular}{|c|c|c|c|c|c|}
\hline Programa & Projetos & Ações & Prazo & Participantes & $\begin{array}{l}\text { Orçamento } \\
\text { Brasileiro (US\$) }\end{array}$ \\
\hline \multirow{7}{*}{ ProSavana } & $\begin{array}{l}\text { ProSavana } \\
\text { PEM (Projeto } \\
\text { de Extensão e } \\
\text { Modelos) }\end{array}$ & $\begin{array}{l}\text { Aumento da produção agrícola } \\
\text { em cada escala de organização } \\
\text { produtiva pela adoção de } \\
\text { modelos de desenvolvimento } \\
\text { agrícola em áreas alvo da região } \\
\text { do ProSavana. }\end{array}$ & 20 anos & $\begin{array}{l}\text { Brasil - ABC, MDA, } \\
\text { ASBRAER, SENAR, } \\
\text { EMATER e } \\
\text { Universidades } \\
\text { Japão - JICA } \\
\text { Moçambique - DNEA }\end{array}$ & Sem definição \\
\hline & $\begin{array}{l}\text { ProSavana PD } \\
\text { (Plano } \\
\text { Diretor) }\end{array}$ & $\begin{array}{l}\text { Formular um Plano Diretor com } \\
\text { vistas ao desenvolvimento } \\
\text { agrícola, que contribua para o } \\
\text { desenvolvimento social e } \\
\text { econômico do Corredor de } \\
\text { Nacala }\end{array}$ & 10 anos & $\begin{array}{l}\text { Brasil - ABC, FGV } \\
\text { Agro } \\
\text { Japão - JICA } \\
\text { Moçambique - MINAG }\end{array}$ & $1.322 .858,08$ \\
\hline & \multirow[t]{5}{*}{$\begin{array}{l}\text { ProSavana PI } \\
\text { (Projeto de } \\
\text { Investigação) }\end{array}$} & $\begin{array}{l}\text { Componente } 1 \\
\text { infraestrutura do IAM dos } \\
\text { centros zonais de Nampula e de } \\
\text { Lichinga }\end{array}$ & \multirow[t]{5}{*}{05 anos } & \multirow{5}{*}{$\begin{array}{l}\text { Brasil - ABC, } \\
\text { EMBRAPA } \\
\text { Japão - JICA } \\
\text { Moçambique - IIAM }\end{array}$} & \multirow{5}{*}{$14.629 .910,00$} \\
\hline & & $\begin{array}{l}\text { Componente } 2 \\
\text { impacto sociais, econômicos e } \\
\text { ambientais }\end{array}$ & & & \\
\hline & & $\begin{array}{l}\text { Componente } 3 \\
\text { gestão territorial }\end{array}$ & & & \\
\hline & & $\begin{array}{l}\text { Componente } 4 \\
\text { sistemas de produção } \\
\text { (excedentes exportáveis) }\end{array}$ & & & \\
\hline & & $\begin{array}{l}\text { Componente } 5 \\
\text { Agricultura familiar }\end{array}$ & & & \\
\hline
\end{tabular}

Fontes: Elaboração própria, com base nas informações dos entrevistados e nas fornecidas pelo Serviço de Informação ao Cidadão, sob o protocolo $\mathrm{n}^{\circ} 09200000380201412$. 
com a participação direta da EMBRAPA na sua execução. O ProSavana PI objetiva a melhoria da capacidade de pesquisa e transferência de tecnologia com vistas ao desenvolvimento da agricultura no Corredor de Nacala, centrando sua atuação nos componentes de fortalecimento institucional, de impactos sociais, de gestão territorial, de sistemas de produção (excedentes exportáveis) e de agricultura familiar. Para a execução do ProSavana PD, foi contratada, por meio de processo licitatório, a organização Fundação Getúlio Vargas (FGV Projetos), que ficou responsável, do lado brasileiro, pela formulação do plano diretor do Programa. O contrato com a FGV foi encerrado em 2014, sendo divulgada uma "versão zero" do plano diretor em março de 2015, com abertura de auscultações públicas para discussão da proposta, até o momento sem uma versão definitiva. O ProSavana PEM ainda está em fase embrionária e visa à criação de modelos de desenvolvimento agrícola comunitários, com melhoria do serviço de extensão agrária no Corredor de Nacala. Por ainda estar em fase de negociação, os valores referentes não foram divulgados, estando envolvidos no projeto, além da ABC, o Ministério de Desenvolvimento Agrário, a Associação Brasileira de Assistência Técnica e Extensão Rural (ASBRAER), o Serviço Nacional de Aprendizagem Rural (SENAR), a Empresa de Assistência • Técnica e Extensão Rural (EMATER) e universidades brasileiras ainda não definidas.

Nota-se que, à medida que o ProSavana avançava, uma forte discussão política em torno do Programa ganhou força. Na perspectiva de que a entrada massiva de capital agroindustrial promoveria a expulsão dos pequenos agricultores de suas terras, muitas organizações não governamentais moçambicanas e brasileiras se manifestaram contra o ProSavana. Inspirado no PRODECER, apesar de os cooperantes brasileiros negarem qualquer correspondência entre os dois projetos, o ProSavana é criticado por, possivelmente, permitir que as mesmas consequências observadas no cerrado brasileiro se configurem na realidade moçambica- na - expropriação de pequenos agricultores e produção de um dano ambiental de grande impacto na região (Clements; Fernandes, 2013; Funada-Classen, 2013; Schlesinger, 2013).

Assim, o Brasil estaria promovendo a exportação das contradições de seu modelo agrário para território moçambicano, com o favorecimento do agronegócio em detrimento dos pequenos produtores locais, ao mesmo tempo em que favoreceria a entrada de capital brasileiro nesse processo. Se, a todo momento, o discurso da cooperação brasileira buscou desvincular seus projetos de interesses econômicos e alinhá-los às diretrizes da Cooperação Sul-Sul, essa separação é inviabilizada no caso do ProSavana. Eventos promovidos pela Agência Brasileira de Cooperação (ABC) - como o "Seminário Internacional Agronegócio em Moçambique: Cooperação Internacional Brasil Japão e Oportunidades de Investimento", realizado em abril de 2011, em São Paulo, com o objetivo de atender ao componente de atração de investimentos em agricultura comercial em Moçambique, através das ações do ProSavana, bem como a realização de visitas de políticos, agricultores e empresários brasileiros a Moçambique - demonstraram o envolvimento da cooperação brasileira na promoção de investimentos naquele país (Schlesinger, 2013).

Mais polêmica foi gerada pelo lançamento do Fundo de Investimentos em Agricultura para o Corredor de Nacala - o Fundo Nacala - pela FGV Projetos, realizado em cerimônia em Brasília e em Maputo, em 2012. Segundo informação do sítio eletrônico da FGV, administradora do Fundo em conjunto com a empresa 4I. GREEN, o Fundo, de natureza privada, tem por objetivo financiar empreendimentos que estimulem o desenvolvimento agrícola e regional da região de Nacala, em Moçambique, estando alinhado com as estratégias apontadas pelo Plano Diretor para o Desenvolvimento da Agricultura do Corredor de Nacala, elaborado pela própria instituição. De acordo com as informações divulgadas na imprensa brasileira, o potencial de desenvolvi- 
mento do Fundo estaria atrelado à "riqueza em recursos naturais da região, que sinaliza não apenas um excelente retorno aos investidores de longo prazo, como o torna um projeto de baixo risco, pois está baseado em um plano de desenvolvimento acordado com o governo moçambicano.” (Agroanalysis, 2015).

Em entrevista concedida ao canal Terra Viva, o coordenador do projeto, Cleber Guarany, estima a movimentação total de US\$500 milhões para desenvolver 300 mil hectares, em culturas de arroz, milho, soja e algodão na primeira fase do projeto. Para atrair investidores ao Fundo, Guarany aponta como vantagens comparativas: a disponibilidade de terras inexploradas; o solo menos ácido que o do cerrado (e que, portanto, exige menos fertilizantes); engajamento dos países parceiros do ProSavana; proximidade com os mercados consumidores, especialmente a China; e a existência de infraestrutura para a comercialização, como o porto de Nacala e uma ferrovia que atravessa todo Corredor. Segundo Guarany, o Fundo prevê a integração do pequeno, médio e grande produtor na mesma cadeia de valor. A integração do pequeno produtor dar-se-ia por meio da abertura de financiamento a juros mais baixos que os de mercado, da assistência técnica ao produtor e da assinatura de um contrato de compra. Essa forma de integração por subcontratação, como analisa Mosca (2014), traz como vantagem ao investidor a redução dos investimentos (principalmente com terras e mão de obra), distribuindo-o com o pequeno produtor, dos conflitos de terras e dos custos de produção, garantindo os melhores preços de compra junto ao pequeno produtor em razão da grande assimetria na capacidade de negociação entre os agentes do lado da oferta e da procura.

Apesar de todos os entrevistados ligados ao governo brasileiro afastarem qualquer relação entre o Fundo Nacala e a cooperação brasileira, o movimento dos atores envolvidos contradiz essa posição. Relatório elaborado pela organização não governamental FASE enumera alguns fatos que colaboram para a falta de cla- reza dos papéis desempenhados pelas esferas pública e privada: 1) o lançamento do Fundo durante viagem oficial do Vice-Presidente brasileiro a Moçambique, na qual foi enfatizado o apoio do governo à iniciativa; 2) a justaposição de papéis desempenhados pela Fundação Getúlio Vargas (FGV) na execução do Programa ProSavana e na concepção do Fundo; 3) a falta de clareza nas declarações oficiais prestadas por membros do governo brasileiro e moçambicano, que vinham associando as iniciativas; 4) a forma de apresentação das informações sobre o Fundo pela FGV Projetos na internet, que vincula as iniciativas; 5) a assimetria de informações entre os três governos envolvidos no ProSavana sobre o Fundo; 6) a ausência de documentos oficiais do Fundo disponíveis para consulta pública; e 7) a cobertura deficiente da mídia sobre o tema (Fase, 2014).

Todos esses fatores, imbricados entre o estabelecimento do agronegócio brasileiro, cristalizado no lançamento do Fundo Nacala, e a cooperação brasileira, por meio do ProSavana, têm levantado importantes questionamentos por parte da sociedade civil moçambicana e também brasileira. Em carta aberta subscrita por várias organizações dos países participantes, em 2013, a preocupação e o repúdio ao projeto foram manifestados aos três Chefes de Estado, alertando para a total ausência de um debate público profundo, amplo, transparente e democrático e para os impactos negativos irreversíveis que podem decorrer do ProSavana, como o surgimento de famílias sem-terra, agravamento da pobreza, destruição dos sistemas de produção familiar, poluição dos ecossistemas e desequilíbrio ecológico.

A repercussão negativa do ProSavana junto à sociedade moçambicana tem surtido algum impacto na sua execução e nos investimentos a ele atrelados. Natália Fingermann (2014) ressalta que as críticas ao programa trouxeram impactos positivos no sentido de aumentar a participação da sociedade civil e aprimorar o grau de transparência da coordenação. Inclusive, para dar maior transparência, foi especialmente criado um sítio eletrônico para divulgação de informações e documentos 
referentes ao programa. Relatório da FASE informa que, em razão da pressão da sociedade civil por mais esclarecimentos sobre o funcionamento do Fundo Nacala e sua relação com a iniciativa governamental, o Fundo não chegou a iniciar suas operações. Assim, observa-se uma grande articulação das organizações não governamentais do campo e da cidade voltada para o aprofundamento das discussões sobre o Programa, o que põe em causa a capacidade de esses governos articularem e satisfazerem os diversos interesses em questão.

\section{CONSIDERAÇÕES FINAIS}

A análise dos projetos da fábrica de medicamentos antirretrovirais e do ProSavana revelam dinâmicas de atuação da cooperação brasileira bastante distintas setorialmente. A cooperação realizada no campo da saúde se caracteriza pela exclusiva presença do Estado na promoção e execução de políticas públicas de atenção do HIV e da AIDS, seja porque há um desinteresse do setor privado, ou os custos impostos são demasiado altos para serem arcados pelo governo moçambicano e sua população disso decorre alto grau de dependência da ajuda externa nesse campo. Diferentemente, no projeto do setor agrícola, a presença do setor \& privado está no cerne do alcance do objetivo ث proposto. Ou seja, sem a participação do setor produtivo agrícola (moçambicano e ou estrangeiro), não haveria a construção de novos moơ delos de desenvolvimento agrícola. Nota-se, cularmente complexas, com a manutenção de grupos de interesse no poder e a integração de outros elementos na estrutura governativa, como quadros da esquerda e integrantes de movimentos sociais. Corroborando o entendimento de Cardoso (2006), a neutralidade ou o afastamento da cooperação em relação a interesses políticos e (ou) econômicos é difícil de ocorrer, ao mesmo tempo em que a interação entre cooperação e negócio é igualmente difícil de ser comprovada institucionalmente, como bem atesta o caso do ProSavana.

O ímpeto do então presidente Lula em promover a cooperação brasileira no continente africano refletiu um momento de maior protagonismo da política externa brasileira, que, por sua vez, incluía outras alianças com países do Sul, voltadas para construção de novas arquiteturas na política e na economia mundiais. A construção do discurso da cooperação brasileira na África e sua operacionalização prestaram-se, notadamente, para que o governo brasileiro angariasse o apoio de alguns países africanos nos pleitos internacionais, como a reivindicação de um assento no Conselho de Segurança da ONU, sem o êxito esperado, e a eleição de representantes brasileiros na direção de importantes organizações, como a Organização das Nações Unidas para a Alimentação e a Agricultura (FAO) e a Organização Mundial do Comércio (OMC). Assim, se a cooperação preconizada pelos países do Sul deveria ser caracterizada pelos ganhos mútuos dos parceiros, esse ganho, do lado brasileiro, foi explicitado no âmbito político. Apesar de não explícitos no discurso da cooperação, os ganhos econômicos também pautaram essa presença, como pode ser analisado por meio dos projetos de instalação da fábrica de medicamentos antirretrovirais e do ProSavana. A análise desses dois projetos permitiu compreender as interfaces entre a cooperação e os negócios brasileiros em Moçambique, expondo as coerências e contradições entre o discurso e a prática da cooperação brasileira.

No projeto de instalação da fábrica de medicamentos ficou evidente que, apesar da 
participação direta de uma empresa brasileira no projeto, a coerência com as diretrizes da cooperação Sul-Sul foi mantida. Os objetivos do projeto se harmonizaram com as prioridades contidas no planejamento do governo moçambicano e não se constatou, do lado brasileiro, a imposição de qualquer condicionalidade para sua viabilização. Assim, a instalação da fábrica pode ser enquadrada como um caso típico de cooperação horizontal. A participação da empresa brasileira Vale S. A., ao invés de significar a existência de algum interesse econômico voltado para a exploração da fábrica, foi o elemento que viabilizou a execução do projeto, mesmo sem dele resultar proveito econômico direto.

Diferentemente, o ProSavana demonstrou uma imbricação entre a cooperação e os negócios brasileiros, mesmo não havendo participação direta de empresas no programa. Os resultados esperados articulavam-se diretamente com a pretensão de investimentos do agronegócio brasileiro em Moçambique, o que foi evidenciado pela criação do Fundo de Nacala. A criação desse fundo de investimentos não seria possível sem a realização de um projeto que o viabilizasse, com a precedência de estudos sobre a gestão territorial e o desenvolvimento tecnológico para a adequação do solo às diferentes culturas a serem produzidas em larga escala. Dessa forma, ao contrário da instalação da fábrica de medicamentos antirretrovirais, o ProSavana vinculou fortemente a cooperação aos interesses econômicos do setor privado brasileiro.

Pode-se, portanto, concluir que as interfaces entre a cooperação e os negócios brasileiros podem assumir diversas matizes, que passam pela vinculação direta, vinculação indireta e, mesmo, podem estar desvinculados. É importante salientar, no entanto, que, apesar de a ação governamental promover tanto cooperação como negócios, isso não significa que eles sejam dependentes. Ou seja, os investimentos brasileiros serão realizados independentemente da existência de projetos de cooperação; da mesma forma que a cooperação poderá ser desenvolvida sem que dela decorram consequências diretas em investimentos. A localização dos investimentos parece ser muito mais definida pela prospecção de vantagens comparativas ou pela própria localização do recurso a ser explorado, como no caso da indústria extrativa mineira, do que em razão da presença de cooperação entre os países. No caso de Moçambique, importantes investimentos brasileiros já haviam sido negociados quando os projetos de cooperação mais significativos começaram a ser executados, ao final do mandato do presidente Lula da Silva. Mais do que coincidir com o momento do aumento da cooperação, os investimentos brasileiros ocorreram em razão do contexto moçambicano de crescimento econômico, de abertura de mercado, de descoberta de importantes reservas de recursos naturais, que favoreceram a atração de investimentos ao país.

Quando a vinculação ocorre, apesar de independente, a cooperação propicia a criação de um ambiente político favorável para a realização de acordos comerciais e investimentos. Como instrumento de política externa, a cooperação permite o alargamento e o aprofundamento das relações entre os países. Isso significa que, diante de situações de impasse ou conflito, o Estado pode ser um intermediador da relação entre setor privado e governo estrangeiro; ou ele funciona como o próprio promotor e garantidor dessa imbricação. O caso do ProSavana é um exemplo que demonstra como a cooperação para o desenvolvimento pode ser utilizada para a expansão do capital, por meio da utilização das capacidades do Estado para fazê-lo. O inverso dificilmente será verdadeiro, com empresas criando um ambiente favorável para a cooperação; entretanto, o projeto da fábrica de medicamentos antirretrovirais demonstrou uma interação possível nesse sentido. Se não fossem os recursos disponibilizados pela Vale - que não auferiu vantagens direitas do projeto -, a instalação e o funcionamento da fábrica não seriam viabilizados. Isso não significa, entretanto, que vantagens indiretas não 
foram possíveis. A participação da empresa brasileira no projeto possibilitou a exploração de uma imagem favorável junto à sociedade moçambicana, demonstrando a responsabilidade social da empresa, fato que ganhou maior importância com as polêmicas decorrentes do reassentamento das famílias deslocadas pela exploração da mina de carvão de Moatize.

Essa ambivalência da existência de interesse ou desinteresse econômico na cooperação, no entanto, não é exclusiva da cooperação brasileira. A história recente de Moçambique é exemplar para se compreender o percurso da cooperação para o desenvolvimento e os diversos interesses que se fazem presentes na ação cooperativa. Justamente por receber uma cooperação condicionada pelos interesses dos países desenvolvidos, Moçambique tem buscado parcerias com países que praticam outro tipo de cooperação, como China, Brasil e Índia. Esses países, apesar de adotar práticas muito diversas, atuam no sentido de fortalecer a atividade estatal, afastando-se, sobretudo, de condicionalidades de natureza política.

No caso brasileiro, a construção de um discurso que busca diferenciar a cooperação brasileira da realizada pelos países desenvolvidos foi importante para o movimento de reaproximação com os países africanos. Ao aliar o discurso da solidariedade à ideia da existência • de uma dívida histórica com os países africaN nos, o Brasil apresenta um discurso revigora造

$\dot{a}$ esse discurso tem sofrido reveses ao longo do

iิ governo Dilma Rousseff, o que pode ser exem-

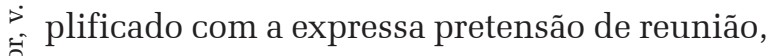
em uma única agência, das atividades de pro-

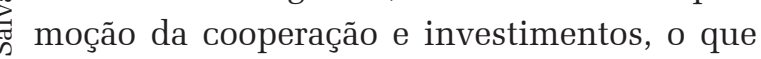
torna indubitável as imbricações entre ambos. Essa mudança de orientação mostra, sobretudo, que as relações entre o Brasil e países do continente africano ainda experimentam a di- nâmica de aproximação e afastamento que as caracterizou no século XX. A tendência é a de que, em um contexto globalizado, esse afastamento seja menos proeminente do que em momentos anteriores.

Recebido para publicação em 19 de setembro de 2015 Aceito em 20 de dezembro de 2015

\section{REFERÊNCIAS}

ABRAHAMSSON, Hans; NILSSON, Anders. Moçambique em transição: um estudo da história de desenvolvimento durante o período 1974-1992. Maputo: Padrigu; CEEI-ISRI, 1994.

AGROANALYSIS. FGV lança fundo pioneiro de investimentos em agronegócio. Disponível em: http://www.agroanalysis.com.br/materia_detalhe. php?idMateria=1313. Acesso em: 09 jan. 2015.

CARDOSO, Fernando Jorge. Diplomacia, cooperação e negócios: o papel dos actores externos em Angola e Moçambique. Lisboa: IEEI, 2006.

CLEMENTS, Elizabeth Alice; FERNANDES, Bernardo Mançano. Estrangeirização, agronegócio e campesinato no Brasil e Moçambique. In: Observador Rural, n. 6, maio 2013. Disponível em: http://www.omrmz.org/images/ publicacoes/Observador_6.pdf. Acesso 05 jan. 2015.

FASE. Fundo Nacala: estrutura original e desdobramentos. Rio de Janeiro, 2014.

FOLHA DE SÃO PAULO. Empreiteiras pagaram quase metade das viagens de Lula ao exterior. Disponível em: http://www1.folha.uol.com.br/poder/2013/03/1250460empreiteiras-pagaram-mais-da-metade-das-viagens-delula-ao-exterior.shtml. Acesso em: 10 jun. 2013.

FUNADA-CLASSEN, Sayaka. Fukushima, ProSAVANA e Ruth First: análise de "Mitos por trás do ProSAVANA" de Natália Fingermann. IDeIAS, Boletim nº51, Maputo, 9 de ago. 2013.

FINGERMANN, Natália. A cooperação trilateral brasileira em Moçambique: um estudo de caso comparado: o ProAlimentos e o Pro Savana. 2014. 274p. Tese (Doutorado em Administração Pública e Governo) - Escola de Administração de Empresas da Fundação Getúlio Vargas.

HANLON, Joseph. Who calls the shots? Londres: James Currey; Indiana University Press, 1991.

INSTITUTO DE PESQUISA ECONÔMICA APLICADA; AGÊNCIA BRASILEIRA DE COOPERAÇÃO. Cooperação brasileira para o desenvolvimento internacional: 20052009. Brasília: IPEA: ABC, 2010.

Cooperação brasileira para o desenvolvimento internacional: 2010. Brasília: IPEA: ABC, 2013.

LOPES, Roberta Nunes. Ogoverno brasileiro e a Cooperação Sul-Sul com Moçambique no campo da saúde pública. 2013. 196p. Dissertação (Mestrado em Administração de Empresas) - Escola de Gestão de Negócios do Programa de Pós-Graduação em Administração da Universidade do Grande Rio, Rio de Janeiro, 2013.

MILHORANCE, Carolina. A política de cooperação do Brasil com a África Subsaariana no setor rural: transferência e inovação na difusão de políticas públicas. Rev. Bras. Polit. Int. v. 56, n. 2, p. 5-22, 2013. 
MINISTÉRIO DA SAÚDE; FIOCRUZ. Projeto de instalação da fábrica de antirretrovirais e outros medicamentos: cooperação técnica internacional Brasil-Moçambique. Disponível em: http://www.deivison.com.br/demos/smm/ relatorio_SMM.pdf. Acesso em: 26 nov. 2015.

MOÇAMBIQUE. Constituição da República. Maputo, 16 nov. 2004

MOSCA, João. Por que é que a produção alimentar não é prioritária? In:

DADA, Yasser Arafat. Bases para uma política agrária em Moçambique. Maputo: Escolar Editora, 2014

OPPENHEIMER, Jochen. Moçambique na era do ajustamento estrutural: ajuda, crescimento e pobreza. Lisboa: ISEG; CEsA, 2006.

PATRIOTA, Thomas Cooper; PIERRI, Francesco Maria. Brazil's cooperation in African agricultural development and food security. In: CHERU, Fantu; MODI, Renu. Agricultural development and food security in Africa. London: Zed Books, 2013. p. 38-56.
PEPFAR. Pepfar Dashboards. Disponível em: http://data.pepfar.net/country/funding?country= Mozambique\&year=2008. Acesso em: 04 jan. 2015.

PROSAVANA. O que é o ProSavana? Disponível em: http:// www.prosavana.gov.mz/index.php? $\mathrm{p}=$ pagina\&id $=27$. Acesso em: 02 jan. 2015.

SCHLESINGER, Sérgio. Cooperação e investimentos do Brasil na África: o caso do ProSavana em Moçambique. Maputo: FASE, 2013.

UNAIDS. Global AIDS Response Progress Report. Country progress report Mozambique. Disponível em: http://www. unaids.org/sites/default/files/country/documents/MOZ

narrative report 2014.pdf. Acesso em 10 jan. 2015. 


\section{BETWEEN THE SOLIDARITY DISCOURSE AND THE PRAGMATIC ACTION OF THE BRAZILIAN COOPERATION IN MOZAMBIQUE: cases of implementation of projects of an antiretroviral drugs factory, and ProSavana}

\author{
Elga Lessa de Almeida
}

The Brazilian cooperation with African countries gained importance during the time Lula da Silva was president, supported by the international solidarity discourse and the existence of a historical debt with Africa, as well as by a practice that seeks, above all, to structure the demands of these countries without imposing any conditions. It is noticeable, however, that the Brazilian presence in Mozambique - a country that received special attention during the Lula administration - points to an ambivalence of this cooperation. At the same time the discourse announces a cooperation that is not connected to economic interests, there is the presence of big Brazilian companies as benefactors in the projects of the cooperation, or even directly invested in the results produced by these projects. In this sense, this article showed this ambivalence and reflected upon it by analyzing two projects that will be significantly important for the Brazilian technical cooperation: a project for the implantation of an antiretroviral drugs factory and the Tripartite Cooperation Program for the Agricultural Development of the Tropical Savannah in Mozambique, the ProSavana.

KeYwORDS: Brazilian cooperation. Mozambique. Drug factory. ProSavana.

\section{ENTRE LE DISCOURS DE LA SOLIDARITÉ ET DE L'ACTION PRAGMATIQUE DE LA COOPÉRATION BRÉSILIENNE AU MOZAMBIQUE: cas de la mise en œuvre de l'usine de projets médicaments antirétroviraux et ProSavana}

\author{
Elga Lessa de Almeida
}

La coopération du Brésil avec les pays africains a gagné un soulagement significatif sur le gouvernement de Lula da Silva, soutenu par le discours de la solidarité internationale et l'existence d'une dette historique à l'Afrique et une pratique qui vise, avant tout, par la structure du secteur aux exigences de ces pays et pas imposer des conditionnalités. Il est entendu, cependant, que la présence brésilienne au Mozambique - un pays qui a reçu une attention particulière dans le gouvernement Lula - pointe vers une ambivalence que la coopération. Alors que le discours se propage coopération non liée à des intérêts économiques, la présence de grandes entreprises brésiliennes comme des bienfaiteurs dans les projets de coopération brésilienne ou même directement intéressés par les résultats produits par les projets est observée. En ce sens, cet article cherche à mettre en évidence et de réfléchir sur cette ambivalence, à travers deux analyse des projets qui permettront d'atteindre une signification importante pour la coopération technique brésilienne: la mise en œuvre du projet d'usine de médicaments antirétroviraux et le Programme de développement de la coopération tripartite l'agriculture tropicale Interests. Savannah au Mozambique - ProSavana.

Mots CLÉs: La coopération brésilienne. Intérêts. Mozambique. Plantes médicinales. ProSavana. Recôncavo da Bahia (UFRB), vinculada ao Núcleo de Estudos Interdisciplinares e Formação Geral NUVEM/CECULT. Dedica-se a pesquisas de caráter interdisciplinar relacionando temáticas como políticas de reconhecimento, políticas públicas, organizações internacionais, movimentos sociais, conferências internacionais e, especialmente no Doutorado, a cooperação Sul-Sul, relações diplomáticas entre Brasil e países africanos e contexto africano contemporâneo. É pesquisadora do Laboratório de Análise Política Mundial - LABMUNDO/UFBA e do Centro de Estudos Internacionais - CEI/IUL. Publicações recentes: Nuevas o viejas relaciones? La cooperación técnica brasileña en Mozambique durante el gobierno de Lula da Silva. Íconos (Quito), v. 51, p. 65-81, 2015; O discurso brasileiro para a cooperação em Moçambique: existe ajuda desinteressada?. Astrolabio (Buenos Aires), v. 10, p. 341-374, 2013. 